\title{
Effect of Inoculum Density of Sclerotium cepivorum on the Ability of Trichoderma koningii to Suppress White Rot of Onion
}

\author{
D. A. Metcalf, Tasmanian Institute of Agricultural Research, New Town Research Laboratories, GPO Box 44, \\ Hobart, Tasmania 7001, Australia; J. J. C. Dennis, Field Fresh Tasmania, PO Box 1283, Devonport, Tasmania 7310, \\ Australia; and C. R. Wilson, Tasmanian Institute for Agricultural Research, University of Tasmania, GPO Box 252- \\ 54, Hobart, Tasmania, 7001, Australia
}

\begin{abstract}
Metcalf, D. A., Dennis J. J. C., and Wilson, C. R. 2004. Effect of inoculum density of Sclerotium cepivorum on the ability of Trichoderma koningii to suppress white rot of onion. Plant Dis. $88: 287-291$.

Amendment of soil with Trichoderma koningii strain Tr5 grown on autoclaved white millet grain provided between 63 and $79 \%$ control of white rot of onion when added to soil containing 10, 25,50 , or 100 sclerotia of Sclerotium cepivorum per kilogram of soil at the time of onion seed sowing. There was no significant difference in the proportion of $S$. cepivorum infections suppressed among the different sclerotial density treatments. Rhizosphere colonization by $T$. koningii $\operatorname{Tr} 5$ was assessed by incubating onion roots sampled from plants growing in soil with the appropriate density of sclerotia, on a Trichoderma selective medium (Rose bengall-Allisanstreptomycin-Previcur agar) developed for the purpose of the study. Trichoderma spp. isolated were typed by comparison of culture morphology as well as polygalacturonase (PG) (EC 3.2.1.15) and pectinesterase (PE) (EC 3.1.1.11) isozyme profiles to the series of one PG and two $\mathrm{PE}$ isozymes known to be produced by $T$. koningii $\operatorname{Tr} 5$. The method was used successfully to assess rhizosphere colonization. Three rates of a millet grain formulation colonized by $T$. koningii $\operatorname{Tr} 5$ were added to soil $(1,590,3,180$, and $4,770 \mathrm{~kg} / \mathrm{ha})$. At the lowest of these rates, $97 \%$ of roots were found to be colonized by isolates which could not be distinguished from $T$. koningii $\operatorname{Tr} 5$, whereas $8 \%$ of the roots from nontreated controls were colonized by such isolates. An objective of the study was to determine whether the ability of $T$. koningii $\operatorname{Tr} 5$ to suppress $S$. cepivorum infections was influenced by increased concentrations of both $S$. cepivorum sclerotia and T. koningii Tr5-colonized millet grain, and it was found that no further improvements in the percentage of disease suppression were recorded as a result of adding T. koningii Tr5-colonized millet to the soil at more than $1,590 \mathrm{~kg} / \mathrm{ha}$ at any of the sclerotium concentrations tested.
\end{abstract}

Additional keywords: Allium, biocontrol

White rot, caused by Sclerotium cepivorum, is a major disease of onion (Allium cepa) production in Tasmania, as well as in many other onion-growing areas of the world. S. cepivorum's sclerotia may rest in the soil for decades and will germinate solely in response to root exudates of plants in the genus Allium (3). The apparent lack of suitable host resistance in commercial onion cultivars and residue problems associated with the few fungicides relatively effective against $S$. cepivorum, make biological control an attractive disease management option for white rot.

Corresponding author: D. Metcalf

E-mail: Dean.Metcalf@dpiwe.tas.gov.au

This study was funded by the Australian Research Council and Horticulture Australia Ltd in collaboration with the Tasmanian Onion Industry Panel and the Tasmanian Farmers and Graziers Onion commodity group.

Accepted for publication 22 October 2003.

Publication no. D-2003-1216-02R

(C) 2004 The American Phytopathological Society
Furthermore, biological control would allow reduction of pesticide use in the environment and provide a market advantage over produce where chemical fungicides have been used.

S. cepivorum infection of onion roots causes extensive disintegration of cortical tissues of the roots, while adjacent epidermal and stele tissues remain intact. The resultant zone of dead and injured cells in the pathway of the infecting hyphae of $S$. cepivorum is protected to some extent from the external soil microbial environment by the intact epidermis (16). Trichoderma koningii strain $\operatorname{Tr} 5$ has been shown to grow into these cortical tissues by colonizing epidermal passage cells, which are smaller than other epidermal cells and have several structural differences to other epidermal cells (18). During this process, $T$. koningii $\operatorname{Tr} 5$ produces chitinolytic enzymes which cause dissolution of $S$. cepivorum hyphae within the onion roots (18). This potential biological control agent does not appear to have the ability to parasitize resting sclerotia of S. cepivorum (14). The ability of $T$. koningii $\operatorname{Tr} 5$ to suppress onion white rot originally was verified in field trials, which demonstrated that amendment of the fungus to the furrow provided a $40 \%$ reduction in infection at harvest (M. Lacey and J. A. L. Wong, unpublished.). The lack of complete control of white rot by $T$. koningii $\operatorname{Tr} 5$ in the field could be attributed to poor colonization of the rhizosphere, or failure to cause lysis of hyphae of $S$. cepivorum as they advanced within the root cortex, or a combination of both.

Initial infestations of $S$. cepivorum in a field usually are limited to patches of less than a few hundred plants when the disease is first noticed. In subsequent Allium crops, inoculum density increases, and disease incidence increases (5). Soil temperature and seasonal time of planting also are important determinants of final disease incidence $(7,15)$. The objective of this study was to determine whether the efficacy of $T$. koningii $\operatorname{Tr} 5$ as a biological control agent of $S$. cepivorum in onion was associated with the level of onion rhizosphere colonization, and to assess the effect of increasing inoculum density of $S$. cepivorum on suppressive activity of $T$. koningii $\operatorname{Tr} 5$. A further objective was to develop and evaluate a technique for tracking rhizosphere colonization by $T$. koningii $\operatorname{Tr} 5$.

\section{MATERIALS AND METHODS}

Inoculum production. Sclerotia of $S$. cepivorum were collected from naturally infected onion bulbs in northwest Tasmania 7 months before the trial. Sclerotia were air dried for 2 weeks and stored in paper bags in darkness at ambient laboratory air temperature $\left(5\right.$ to $\left.25^{\circ} \mathrm{C}\right)$. Inoculum of $T$. koningii $\operatorname{Tr} 5$ was produced by adding $\operatorname{Tr} 5$ as a 5-mm cube of soil agar (16) to an autoclaved 5-liter conical flask containing $1 \mathrm{~kg}$ of white millet, $2.5 \mathrm{~g}$ of Phostrogen plant food (Monsanto, Melbourne, Australia), and $500 \mathrm{ml}$ of tap water. Cultures were incubated in darkness at $20^{\circ} \mathrm{C}$ until sporulation (3 weeks) and air dried at ambient temperature for 3 days before use. Inoculum density was confirmed by dilution plating on pectin agar (13) which consisted of $0.9 \mathrm{~g}$ of $\mathrm{NH}_{4} \mathrm{H}_{2} \mathrm{PO}_{4}, 2.0 \mathrm{~g}$ of $\left(\mathrm{NH}_{4}\right)_{2} \mathrm{HPO}_{4}, 0.1 \mathrm{~g}$ of $\mathrm{MgSO}_{4} 7 \mathrm{H}_{2} \mathrm{O}, 0.5 \mathrm{~g}$ of $\mathrm{KCl}, 10.0 \mathrm{~g}$ of citrus pectin (Sigma, Castle Hill, Australia), and 1 liter of distilled water, adjusted to $\mathrm{pH} 4.0$ before being added to $30 \mathrm{~g}$ of agar and autoclaved. The millet formulation contained $5.6 \times 10^{5}$ propagules $/ \mathrm{g}$. 
Trichoderma selective medium. Rose bengall-Allisan-streptomycin-Previcur (RASP) selective medium (13) consisted of: $2.0 \mathrm{~g}$ of $\left(\mathrm{NH}_{4}\right)_{2} \mathrm{SO}_{4}, 4.0 \mathrm{~g}$ of $\mathrm{KH}_{2} \mathrm{PO}_{4}$, $6.0 \mathrm{~g}$ of $\mathrm{Na}_{2} \mathrm{HPO}_{4}, 0.2 \mathrm{~g}$ of $\mathrm{FeSO}_{4} 7 \mathrm{H}_{2} \mathrm{O}, 1$ $\mathrm{mg}$ of $\mathrm{CaCl}_{2}, 10 \mu \mathrm{g}$ of $\mathrm{H}_{3} \mathrm{BO}_{3}, 10 \mu \mathrm{g}$ of $\mathrm{MnSO}_{4}, 70 \mu \mathrm{g}$ of $\mathrm{ZnSO}_{4}, 1$ liter of distilled water, $20 \mathrm{~g}$ of agar, and $5 \mathrm{~g}$ of cellulose powder (Sigma Australia); adjusted to $\mathrm{pH}$ 4.0 before autoclaving. After the medium cooled to $70^{\circ} \mathrm{C}, 10 \mathrm{ml}$ of a sterile distilled water stock solution containing fungicides and antibiotics was added to provide the following concentrations per liter: $0.05 \mathrm{~g}$ of streptomycin sulphate, $0.016 \mathrm{~g}$ of rose bengal, $0.004 \mathrm{~g}$ of Allisan (dichloran at 750 g/liter; Ag-Chem Pty, Ltd., Parafield Gardens, Australia); $3.2 \mathrm{ml}$ of Previcur (propamocarb at 600 g/liter; Schering Pty, Ltd., Frankfurt, Germany).

Trial preparation. The soil used for the trial was a Red Ferrosol taken from a pasture field in northwest Tasmania without recent history of cropping $(\mathrm{pH}$ 6.2). Five 200-g composite samples of the soil were sieved and examined by the methods of McCain (12) to ensure that no sclerotia of $S$. cepivorum were present. Black plastic soil bags, $20 \mathrm{~cm}$ diameter by $34 \mathrm{~cm}$ deep (Waratah Pty, Ltd.), which held $8 \mathrm{~kg}$ of soil (air dry weight) were used as pots. Sclerotia of $S$. cepivorum were added at 0,10 , 25,50 , and 100 sclerotia/kg of soil. Fertilizer (5 $\mathrm{g}$ of NPK 8:4:10) and sclerotia were mixed thoroughly with the soil, then placed in the soil bags. Millet colonized by
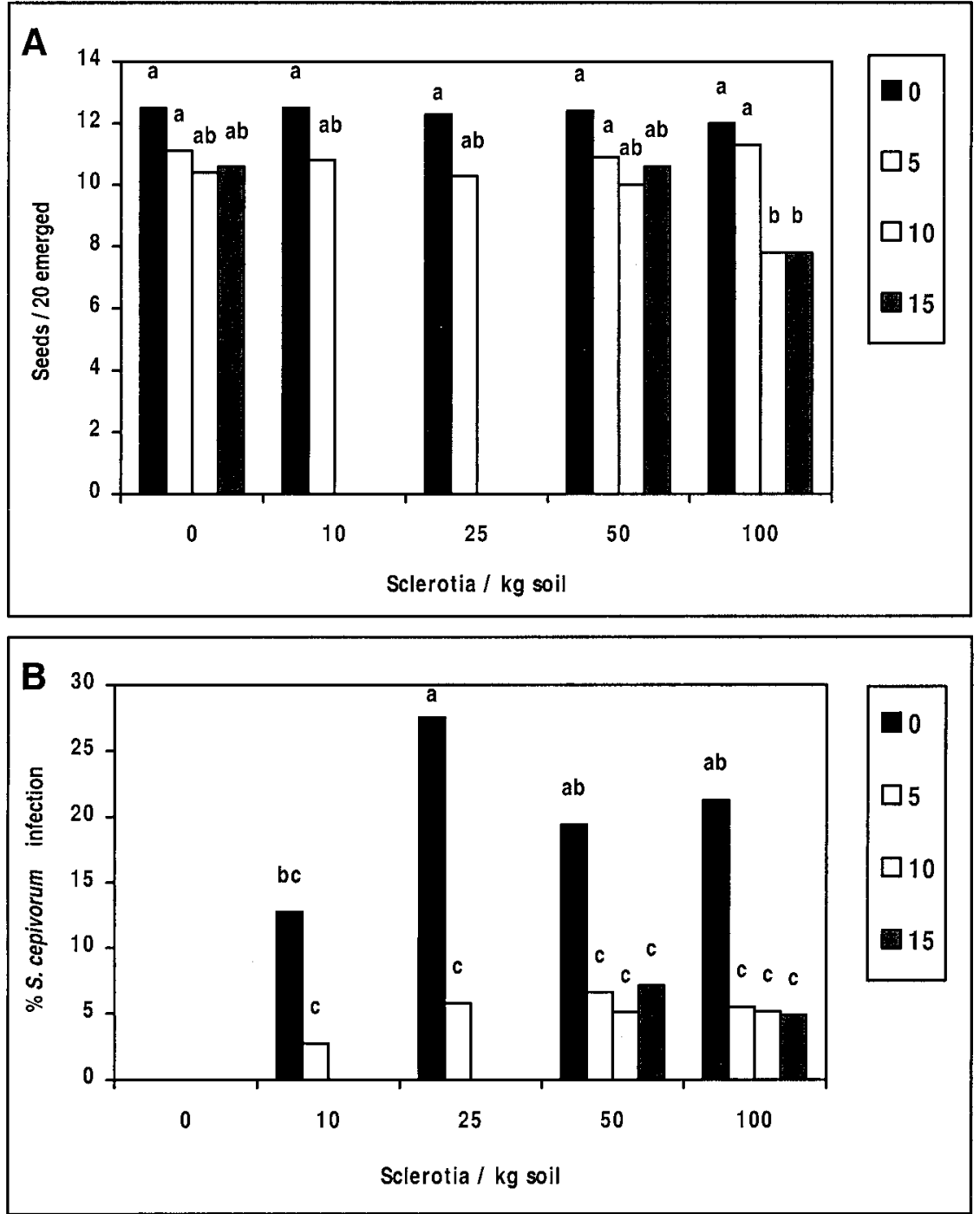

Fig. 1. A, Effects of inoculum density of sclerotia of Sclerotium cepivorum, and amendment of millet grain colonized by Trichoderma koningii $\operatorname{Tr} 5$ at 5, 10, or $15 \mathrm{~g} / \mathrm{soil}$ bag, on emergence of onion seedlings. Columns marked by the same letter are not significantly different according to least significant difference $($ LSD), $\mathrm{P}=0.05=2.79$, error mean square $=9.99$. B, Percentage infection of onion seedlings by $S$. cepivorum until destructive sampling 29 weeks after sowing. Columns marked by the same letter are not significantly different according to LSD, $\mathrm{P}=0.05$, error mean square $=136.62$. Due to poor emergence in some treatments, replicates where fewer than five seedlings had emerged were excluded from the analysis of percentage infection, resulting in some treatments having 8 or 9 replicates rather than 10 . LSD was calculated for unequally replicated means (20). LSD, P $=0.05$, ranged between 10.36 when comparing two treatments with 10 replicates and 11.60 when comparing two treatments with 8 replicates.

T. koningii $\operatorname{Tr} 5$ was added at 0 or $5 \mathrm{~g}$ $(1,590 \mathrm{~kg} / \mathrm{ha}), 10 \mathrm{~g}(3,180 \mathrm{~kg} / \mathrm{ha})$, or $15 \mathrm{~g}$ $(4,770 \mathrm{~kg} / \mathrm{ha})$ per bag. The two higher rates of $T$. koningii $\operatorname{Tr} 5$-colonized millet were not tested in the soils amended with 10 and 25 sclerotia $/ \mathrm{kg}$ of soil. This resulted in a total of 16 treatments. Trials were sown on 24 September 1995 (spring). Twenty seed of the cultivar "regular creamgold" were sown in each bag at a depth of $1 \mathrm{~cm}$ below the soil surface. $T$ koningii $\operatorname{Tr} 5$ inoculum was placed among the seed before the top $1 \mathrm{~cm}$ of soil was added. Each treatment was replicated 10 times. Because of concerns that soil bags located at the outside of the trial block would be exposed to higher soil temperature as a result of sunlight on the black plastic, the outer soil bags were surrounded by hessian sacks filled with pine bark. To reduce the possibility of spores of T. koningii Tr5 spreading from treated to nontreated soil bags, all untreated soil bags were placed in five regularly spaced groups within the block of treated soil bags and were separated from the treated soil bags using hessian sacks. Within this layout, all bags were arranged randomly. The trial was located outdoors in open sunlight.

Emergence of onion seedlings was recorded 6 weeks after sowing. Plants in the trial were examined for symptoms of white rot at fortnightly intervals and infected seedlings were tagged and counted. Seedlings killed by factors other than infection by $S$. cepivorum (e.g., by insects) also were recorded separately. The trial was destructively assessed on 16 April 1996 (29 weeks after sowing). Plants were assessed as being infected with $S$. cepivorum if sclerotia were visible on the bulb base, or infected by other disorders, or healthy. Statistical analysis was performed using the one-way analysis of variance with mean separation by least significant difference (LSD) for seedling emergence and percentage of infection values. Bags in which five or fewer seedlings had emerged were not included in calculating the percentage of seedlings infected by $S$. cepivorum. This resulted in some treatments having 8,9 or 10 replicates; therefore, the LSD test was adjusted for unevenly replicated means (20). Because the data were distributed normally, no transformations of percentage values were performed.

Assessment of root colonization by $T$. koningii Tr5. Four hundred onion root samples were taken from the trial to assess rhizosphere colonization in $T$. koningii Tr5-amended treatments compared with nontreated control treatments. This comprised 5 onion root samples collected from each soil bag in the eight treatments which received either 0 or 100 sclerotia $/ \mathrm{kg}$ of soil. Each plant was uprooted and a section of root approximately $5 \mathrm{~cm}$ long was excised aseptically directly below the base plate by inserting it into a snap seal plastic bag and squeezing the bag's seal mecha- 
nism to cut the root from the bulb immediately below the base plate. The top $1 \mathrm{~cm}$ of each root sample was removed aseptically from the lower few centimeters of root and placed in the center of a plate of RASP selective medium without washing or surface sterilization, before being incubated for 14 days at $25^{\circ} \mathrm{C}$. Each plate then was assessed and placed in one of three categories: category 1, no Trichoderma spp. isolated, category 2, Trichoderma spp. isolated which were morphologically different than T. koningii Tr5, or category 3 , Trichoderma spp. isolates which were morphologically indistinguishable from $T$. koningii Tr5. This assessment was based on colony morphology (e.g.; color of sporulation, structure of the conidiophore, pattern of sporulation). To test the accuracy of the morphological categories, polygalacturonase (PG) and pectinesterase (PE) isozyme profiles (6) of 104 isolates, which comprised 13 randomly selected isolates from each of the eight treatments where 0 or 100 sclerotia/ $/ \mathrm{kg}$ of soil had been added to the soil bags, were compared with the isozyme profile of $T$. koningii Tr5. A 2-mm cube of colonized agar of each test isolate was added to $2 \mathrm{ml}$ of pectinase medium (16) in a 5-ml Bijou bottle and incubated for 7 days at $25^{\circ} \mathrm{C}$. The PG and PE isozymes produced by $\operatorname{Tr} 5$ were characterized by incubation of T. koningii $\operatorname{Tr} 5$ in pectinase medium for 4 , 7,14 , or 18 days before preparing isozyme profiles by the methods of Cruickshank and Pitt (6).

\section{RESULTS}

Seedling infection. The results for seedling emergence and incidence of plants infected by $S$. cepivorum in soils containing $0,10,25,50$, and 100 sclerotia/ $\mathrm{kg}$ of soil, and with $T$. koningii $\operatorname{Tr} 5$ applied at one of three rates, are presented in Figure 1A. The percentage of seedling emergence was low (39 to $63 \%$ ) relative to what normally can be expected of machine-sown onion seed. When $S$. cepivorum was applied at the highest inoculum density (100 sclerotia/kg of soil) and $\operatorname{Tr} 5$ was applied at
10 and $15 \mathrm{~g} / \mathrm{soil}$ bag, significantly lower emergence (7.8 seedlings/soil bag) was recorded than when $\operatorname{Tr} 5$ was applied at 5 g/soil bag (11.3 seedlings/soil bag) or not applied (12 seedlings/soil bag).

The mean disease incidence of $S$. cepivorum infection among plants in soil bags containing 10 sclerotia $/ \mathrm{kg}$ of soil was significantly lower (12.75\% infection) than in those containing 25 sclerotia $/ \mathrm{kg}$ (27.53\% infection). No further increase in the percentage of seedlings infected by white rot was recorded in soil bags amended with 50 and 100 sclerotia $/ \mathrm{kg}$ of soil (Fig. 1B).

In soil containing 10 sclerotia/ $\mathrm{kg}$ amended with $5 \mathrm{~g}$ of millet colonized by $T$. koningii $\operatorname{Tr} 5$, incidence of white rot was significantly reduced by $78.5 \%$. In soil containing 25 sclerotia/kg of soil, incidence of white rot in the T. koningii $\operatorname{Tr} 5$ amended treatment was significantly reduced from $27.5 \%$ in soil without $T$. koningii $\operatorname{Tr} 5$ to $5.7 \%$ in soil with the biological control agent. This was a proportional reduction almost identical to that in soil containing 10 sclerotia/ $\mathrm{kg}$ of soil. In soil containing 50 sclerotia/kg of soil, incidence of white rot was reduced from 19.4 to $6.6 \%$ when $5 \mathrm{~g}$ of $T$. koningii $\operatorname{Tr} 5$ inoculum was added to each pot, and to $5.1 \%$ when $10 \mathrm{~g}$ of the biocontrol agent was added. At the 15-g rate, the incidence of infection was $7.1 \%$, which was not significantly different than the 5- and 10-g rates of amendment. In soil amended with 100 sclerotia/kg of soil, the percentage of plants infected by $S$. cepivorum was reduced by $74 \%$ at the 5 -g rate of addition of T. koningii $\operatorname{Tr} 5$ compared with the nonamended control treatment. In soils containing 100 sclerotia $/ \mathrm{kg}$, the percentage of plants infected by white rot was significantly reduced from $21.29 \%$ infection in the nontreated control treatment to $5.50 \%$ white rot infection among plants amended with the 5-g rate of the $T$. koningii $\operatorname{Tr} 5$ inoculum (Fig. 1B).

Root colonization and isolate identification. At all three rates of amendment with $T$. koningii $\operatorname{Tr} 5$, isolates morphologi- cally indistinguishable from $T$. koningii Tr5 were present on at least $92 \%$ of the root samples (Table 1). Trichoderma spp. were present on $59 \%$ of the root samples taken from nontreated controls, and isolates which could not be distinguished from T. koningii $\operatorname{Tr} 5$ were detected on $8 \%$ of the nontreated control root samples. At least 10 morphologically distinct colony types were noted. From 11 of the 400 root samples, two Trichoderma isolates were detected growing from a single root sample, but these colonies tended to grow on separate parts of the agar plate and produced distinct colony boundaries where they met. When this occurred, both isolates were included in the counts under the appropriate Trichoderma spp. category. This resulted in mean total isolation figures in excess of 5.0 in two treatments $(0$ sclerotia/kg of soil amended with 10 and $15 \mathrm{~g}$ of T. koningii $\operatorname{Tr} 5$; Table 1).

When T. koningii $\operatorname{Tr} 5$ was incubated in pectinase medium for $4,7,14$, or 18 days, isozymes of $\mathrm{PE}$ of $\mathrm{Rf} 0.17$ (ranging from 0.08 to 0.18 ) and 0.22 (ranging from 0.20 to 0.25 ) and $\mathrm{PG}$ Rf 0.30 (ranging from 0.20 to 0.46 ) were detected (Fig. 2). Isozyme profiles of 26 of the 104 isolates selected for isozyme profiling are presented in Figure 3. These isolates are from two treatments which had 0 sclerotia $/ \mathrm{kg}$ of soil with no $T$. koningii $\operatorname{Tr} 5$ inoculum added, and 100 sclerotia/kg of soil with 15 $\mathrm{g}$ of $T$. koningii $\mathrm{Tr} 5$ added. Of the 77 isolates assessed to be morphologically similar to T. koningii Tr5, two produced banding patterns which included isozymes not known to be produced by $T$. koningii $\operatorname{Tr} 5$. For example, isolate P671e produced a PG of Rf -0.06 and PE of Rf 0.30 (Fig. 3), and isolate N655e produced a PG 0.18 and -0.10 (not presented). Of 23 isolates assessed to be morphologically different than T. koningii $\mathrm{Tr} 5,17$ produced isozymes not known to be produced by $T$. koningii $\operatorname{Tr} 5$, and 6 (A530e, A527d, A525c, A522e, A522a, and A521b in Fig. 3) produced isozymes profiles which were indistinguishable from the isozyme profile of $T$. koningii $\operatorname{Tr} 5$.

Table 1. Average number of Trichoderma spp. and of Trichoderma isolates morphologically similar to T. koningii Tr5 which were isolated from five root

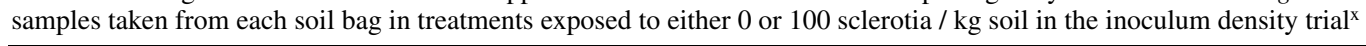

\begin{tabular}{|c|c|c|c|c|c|}
\hline Treatment $^{\mathbf{y}}$ & Sclerotia/kg & $\begin{array}{c}\text { Tr5 rate } \\
\text { (g/soil bag) }\end{array}$ & $\begin{array}{c}\text { Mean no. of } \\
\text { Trichoderma } \text { isolations }{ }^{\mathrm{z}}\end{array}$ & $\begin{array}{c}\text { Mean no. of isolates of } \\
T . \text { koningii } \operatorname{Tr} 5 \text { type }\end{array}$ & $\begin{array}{l}\text { Isolates indistinguishable } \\
\text { from } T \text {. koningii } \operatorname{Tr} 5(\%)\end{array}$ \\
\hline $\mathrm{A}$ & 0 & 0 & $3.3 \mathrm{~b}$ & $0.3 \mathrm{~b}$ & 6 \\
\hline B & 0 & 5 & $4.8 \mathrm{a}$ & $4.8 \mathrm{a}$ & 96 \\
\hline $\mathrm{C}$ & 0 & 10 & $5.3 \mathrm{a}$ & $4.9 \mathrm{a}$ & 98 \\
\hline $\mathrm{D}$ & 0 & 15 & $5.3 \mathrm{a}$ & $4.8 \mathrm{a}$ & 96 \\
\hline M & 100 & 0 & $2.6 \mathrm{~b}$ & $0.5 \mathrm{~b}$ & 10 \\
\hline $\mathrm{N}$ & 100 & 5 & $5.0 \mathrm{a}$ & $4.9 \mathrm{a}$ & 98 \\
\hline $\mathrm{O}$ & 100 & 10 & $5.0 \mathrm{a}$ & $4.6 \mathrm{a}$ & 92 \\
\hline $\mathrm{P}$ & 100 & 15 & $5.0 \mathrm{a}$ & $4.7 \mathrm{a}$ & 94 \\
\hline $\operatorname{LSD}(P=0.05)$ & $\ldots$ & $\ldots$ & 0.596 & 0.818 & $\ldots$ \\
\hline Error mean square & $\ldots$ & $\ldots$ & 0.837 & 0.445 & $\ldots$ \\
\hline
\end{tabular}

${ }^{\mathrm{x}}$ Five root samples were taken from each soil bag in the treatment, and the top $1 \mathrm{~cm}$ of the root was incubated on Rose bengall-Allisan-streptomycinPrevicur medium. Values followed by the same letter in the same column are not significantly different.

y $\mathrm{LSD}=$ least significant difference.

z Values greater than 5 sometimes have been obtained where more than one isolate grew from a single root segment sample. 


\section{DISCUSSION}

This study demonstrated the relationship between the inoculum density of $S$. cepivorum and the ability of $T$. koningii $\operatorname{Tr} 5$ to suppress infection of onion seedlings by this pathogen. The efficacy of $T$. koningii Tr5 remained relatively constant at between 63.2 to $79.0 \%$, whether the soil contained 10 or 100 sclerotia $/ \mathrm{kg}$ soil. Root colonization by $T$. koningii $\operatorname{Tr} 5$ averaged $97 \%$ in pots amended at the lowest rate of T. koningii $\operatorname{Tr} 5$-colonized millet $(1,590$ $\mathrm{kg} / \mathrm{ha}$ ); therefore, additional disease suppression seems unlikely at the higher rates of amendment. The failure of $T$. koningii $\operatorname{Tr} 5$ to provide more than $79 \%$ suppression of white rot indicates failure to successfully challenge and suppress approximately one in five $S$. cepivorum infections which developed in the roots. These failures may be associated with sclerotia located near the soil surface which directly infect the bulb base, where T. koningii $\operatorname{Tr} 5$ would have limited opportunity to inhibit the infection compared with infections progressing within the root cortex and stele from infection sites deeper in the soil (18). Evaluation of the ability of T. koningii $\operatorname{Tr} 5$ to suppress infections emanating from different depths in the rhizosphere is warranted. It is also unclear whether other environmental factors (e.g., soil temperature) may influence the ability of $T$. koningii $\operatorname{Tr} 5$ to cause lysis of invading $S$. cepivorum hyphae.

One of the goals of the trial was to establish whether a sclerotial density threshold existed beyond which T. koningii Tr5 was of limited efficacy. Infection of nonamended control plants by $S$. cepivorum in soil containing 50 and 100 sclerotia/kg of soil was lower than expected, given that

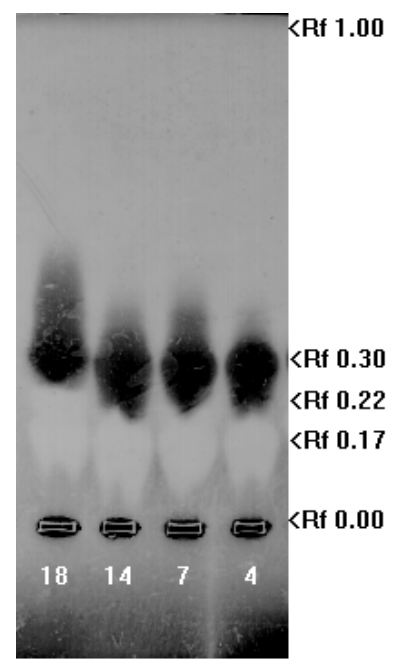

Fig. 2. Trichoderma koningii $\operatorname{Tr} 5$ polygalacturonase (PG, dark zones) and pectin esterase (PE, light zones) profiles, following 4, 7, 14, and 18 days of incubation at $25^{\circ} \mathrm{C}$ in pectinase medium. T. koningii $\operatorname{Tr} 5$ produced two isozymes of PE Rf 0.17 (ranging from 0.08 to 0.18 ) and 0.22 (ranging from 0.20 to 0.25 ) and one isozyme of PG Rf 0.30 (ranging from 0.20 to 0.46 ). disease incidence was $27.53 \%$ in soil containing 25 sclerotia/kg of soil. Higher infection rates have been reported in soils containing similar numbers of sclerotia. For example, $68 \%$ infection was recorded in soil containing 10 sclerotia/kg of soil (10) and $87 \%$ infection was observed in soil containing 68 sclerotia/kg of soil (5). The age of sclerotia and the history of exposure to differences in moisture and temperature affect the proportion of sclerotia which germinate $(2,4,8,19)$. Sclerotia used in this trial were approximately 7 months old at the time the trial was established and had been stored in nonsterile dry conditions, which might not provide appropriate conditioning for optimum germination. In Tasmania, the time of planting onion seed is an important determinant of disease incidence. May (autumn) sowings tend to be more severely infected than August and September (late winter/early spring) sowings when the patho-

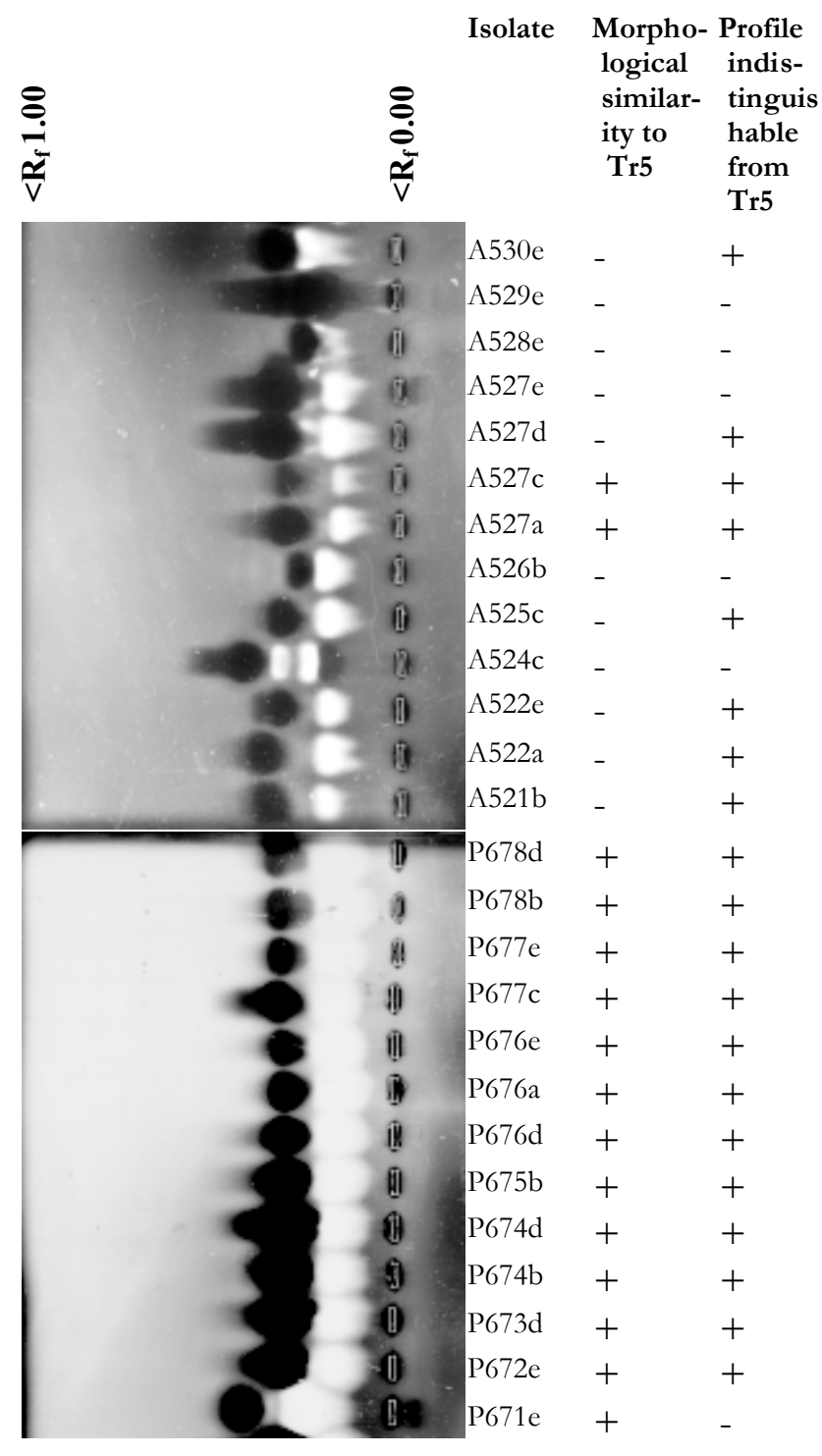

Fig. 3. Polygalacturonase (PG) and Pectin esterase (PE) profiles of Trichoderma spp. isolated from onion roots, prepared following incubation in pectinase medium for 7 days at $25^{\circ} \mathrm{C}$. Dark zones indicate PG, light zones indicate PE. Isolates with identification numbers beginning with $\mathrm{A}$ and $\mathrm{P}$ are the 13 subsamples selected from treatments $\mathrm{A}$ and $\mathrm{P}$ as listed in Table 1. 
previous trials in commercial onion fields, it was found that no more than $30 \%$ of roots examined were colonized by native Trichoderma spp. (13). The soil used in the study may have had a higher degree of natural disease suppressiveness than soil from a regularly cultivated field. Since completion of this study, one Trichoderma sp. isolated during these experiments was screened as a biological control agent for white rot, and provided over $91 \%$ disease suppression in commercial-scale field trials (17). In other trials, it was found that $73 \%$ of the sclerotia of S. cepivorum decayed between planting and final disease incidence assessment when the sclerotia were buried in soil bags of the same soil used in this trial where no onions were sown (13). Substantial decay of the sclerotia of $S$. cepivorum during the first 12 months of burial has been reported (1) and could contribute to the low incidence of white rot observed in this study. Similar trials in soils with a history of chemical application and cultivation would make an interesting comparison to evaluate soil health and natural disease suppressiveness.

The morphological assessment used to differentiate $T$. koningii $\operatorname{Tr} 5$ from other Trichoderma isolates was shown to be adequate, but not infallible. Two of the 77 isolates assessed to be morphologically indistinguishable from $T$. koningii $\operatorname{Tr} 5$ had isozyme profiles which were different than T. koningii $\operatorname{Tr} 5$. The rate of error may be higher, because 6 of 23 isolates (26\%) which were morphologically different than T. koningii $\operatorname{Tr} 5$ produced isozyme profiles which would have failed to show that they were not $T$. koningii $\operatorname{Tr} 5$, had they not been morphologically distinct. The combination of root sampling and isolation using RASP medium, with morphological and PG and PE isozyme typing, has successfully allowed tracking of rhizosphere colonization by $T$. koningii $\operatorname{Tr} 5$. These methods are advantageous because they can be used to track root colonization by Trichoderma spp. in commercial crops, whereas genetically engineered markers such as GUS (9) are not acceptable for commercial applications in Australia, and also because molecular probes, although more sensitive, may detect nonviable inoculum and may provide erratic results when testing different soil types. It is not known whether the $8 \%$ of the Trichoderma isolates that were indistinguishable from $T$. koningii $\operatorname{Tr} 5$ found on onion roots in the nontreated control soil bags had colonized these soil bags by airborne spore dispersal, or were native to the soil. Sequence analysis of the isolates might further determine whether these isolates were genetically homologous to $T$. koningii $\operatorname{Tr} 5$; however, this would not determine their source of origin.

Field trials from the 1994-95 season indicated that the proportion of onion roots on which $T$. koningii $\operatorname{Tr} 5$ became established was less than $10 \%$ when $T$. koningii Tr5-colonized millet was added to the furrow at the time of sowing at $110 \mathrm{~kg} / \mathrm{ha}$ (13). For this reason, the rate of amendment with $T$. koningii $\operatorname{Tr} 5$ was increased in the present experiments. The 5-g rate $(1,590 \mathrm{~kg}$ of colonized millet/ha) introduced $0.06 \%$ by weight of $T$. koningii $\operatorname{Tr} 5$ colonized millet into the soil. Comparable rates have been used in other studies (11). For commercialization, the rate would need to be lower (a maximum of 600 $\mathrm{kg} / \mathrm{ha}$ ) due to production and transport costs, as well as the limited volume of seed drill fertilizer boxes by which the inoculum would be applied.

The limited reduction in seedling emergence recorded after $T$. koningii Tr5 was applied at the higher rates is unlikely to impede commercialization of this biological control agent, because the trend was not observed in subsequent trials in which T. koningii $\operatorname{Tr} 5$ inoculum at 300 to 600 $\mathrm{kg} / \mathrm{ha}$ was applied (14). Light reduction in emergence would not be a practical concern to Tasmanian onion growers who regularly sow more seed than is required to accommodate seedling mortality during selective herbicide operations.

\section{ACKNOWLEDGMENTS}

We thank J. A. L. Wong and R. H. Cruickshank, who were instrumental in the project's initiation; and C. Russell, H. Blackburn, S. Pethybridge, and A. Quarry for assistance in setting up the pot trial.

\section{LITERATURE CITED}

1. Alexander, B. J. R., and Stewart, A. 1994. Survival of sclerotia of Sclerotinia and Sclerotium spp. in New Zealand horticultural soil. Soil Biol. Biochem. 26:1323-1329.

2. Brix, H. D., and Zinkernagel, V. 1992. Effects of cultivation, conditioning, and isolate on sclerotium germination in Sclerotium cepivorum. Plant Pathol. 41:13-19.

3. Coley-Smith, J. R., and Holt, R. W. 1966. The effect of species of Allium on germination in soil of sclerotia of Sclerotium cepivorum Berk. Ann. Appl. Biol. 60:109-115.

4. Coley-Smith, J. R., Parfitt, D., Taylor, I. M., and Reese, R. A. 1987. Studies of dormancy in sclerotia of Sclerotium cepivorum. Plant Pathol. 36:594-599.
5. Crowe, F. J., Hall, D. H., Greathead, A. S., and Baghott, K. G. 1980. Inoculum density of Sclerotium cepivorum and the incidence of white rot in onions and garlic. Phytopathology 70:65-69.

6. Cruickshank, R. H., and Pitt, J. I. 1987. Identification of species in Penicillium subgenus Penicillium by enzyme electrophoresis. Mycologia 79:614-620

7. Dennis, J. J. 2001. Progress toward an integrated control strategy for onion white rot disease, including the use of artificial germination stimulants. Acta Hortic. 555:117-120.

8. Gerbrandy, Sj. J. 1992. Effects of different temperature treatments on dormancy of sclerotia of ten isolates of Sclerotium cepivorum. Neth. J. Plant Pathol. 98:269-276.

9. Green, H., and Funck-Jensen, D. 1995. A tool for monitoring Trichoderma harzianum: II. The use of a GUS transformant for ecological studies of the rhizosphere. Phytopathology 85:1436-1440.

10. Hall, D., and Sommerville, P. 1983. Effect of inoculum potential on control of white rot with fungicides. Pages 113-114. in: Proc. Second Int. Workshop on Allium White Rot. P. B. Adams and A. R. Entwistle, eds. Beltsville, MD.

11. Kay, S. J., and Stewart, A. 1994. Evaluation of fungal antagonists for control of onion white rot in soil box trials. Plant Pathol. 43:371-377.

12. McCain, A. H. 1967. Quantitative recovery of sclerotia of Sclerotium cepivorum from field soil. (Abstr.) Phytopathology 57:1007.

13. Metcalf, D. A. 1997. Biological control of onion white root rot (Sclerotium cepivorum) using Trichoderma koningii. Ph.D. thesis, University of Tasmania, Australia.

14. Metcalf, D. A. Development of biological control agents which control onion white root rot under commercial field conditions. In: Proc. Eighth Int. Workshop on Allium White Rot. M. R. McDonald and F. J Crowe, eds. Harris Ranch, CA. In press.

15. Metcalf, D.A., and Dennis, J. J. C. 2000. Developing a management strategy for white rot and Botrytis in onions. Final Report to Horticulture Australia Ltd. on Project VG423. Horticulture Australia Pty Ltd., Sydney, Australia.

16. Metcalf, D. A., and Wilson C. R. 1999. Histology of Sclerotium cepivorum infection of onion roots and the spatial relationships of pectinases in the infection process. Plant Pathol. 48:445-452.

17. Metcalf, D. A., and Wilson, C. R. 2001. Progress toward a biological control system for onion white root rot in Tasmania. Acta Hortic. 555:123-127.

18. Metcalf, D. A., and Wilson, C. R. 2001. The process of antagonism of Sclerotium cepivorum in white rot affected onion roots by Trichoderma koningii. Plant Pathol. 50:249-257.

19. Papavizas, G. C. 1977. Survival of sclerotia of Macrophomina phaseolina and Sclerotium cepivorum after drying and wetting treatments. Soil Biol. Biochem. 9:343-348.

20. Steele R. G. D., and Torrie J. H. 1980. Testing unequally replicated means. Page 191 in: Principles and Procedures of Statistics. A Biometrical Approach. 2nd ed. McGraw Hill International, Singapore. 